\title{
Investigation of Relationship between Identity Styles and Achievement Motivation in High School Students in the City of Sari
}

\section{Fatemeh Ghasempour (BSc) ${ }^{1}$, Maryam Azimi $(\mathrm{MSc})^{2, *}$, Akram Sanagoo $(\mathbf{P h D})^{3}$, Ali Akbar Mobasseri (Msc) ${ }^{4}$}

${ }^{1}$ Islamic Azad University Sari, Sari, Iran

${ }^{2}$ Critical Care Nursing, Pediatric hospital Imam Hossin, Esfahan University of Medical Sciences, Esfahan, Iran

${ }^{3}$ Nursing Research Center, Golestan University of Medical Sciences, Gorgan, Iran.

${ }^{4}$ Shahid Vatanpor Training Center, Esfahan, Iran

* Corresponding Author: Maryam Azimi, Critical Care Nursing, Pediatric Hospital Imam Hossin, Esfahan University of Medical Sciences, Esfahan, Iran.Email: azimi8389@yahoo.com

\begin{tabular}{|c|c|}
\hline & Abstract \\
\hline $\begin{array}{l}\text { Received: 02/10/2016 } \\
\text { Accepted: } 10 / 03 / 2017\end{array}$ & \multirow[b]{2}{*}{$\begin{array}{l}\text { Background and Objective: Academic achievement is considered as an } \\
\text { important task for teens under the effect of multiple personal and social } \\
\text { factors. Identity styles and achievement motivation, as psychological } \\
\text { structures, are of two categories of these factors. Therefore, the aim of this } \\
\text { study was to investigate the relationship between identity styles and } \\
\text { achievement motivation among high school students in the city of Sari. } \\
\text { Materials and Methods: The current study was methodologically } \\
\text { descriptive-correlational. The population of the study included all students } \\
\text { of the high schools. The method of sampling was stratified random } \\
\text { sampling, which } 379 \text { participants were selected based on Krejcie and } \\
\text { Morgans. Berzonsky's identity style and Hermen's achievement motivation } \\
\text { questionnaires were used to collect data. The data were analyzed by } \\
\text { Pearson correlation coefficient and independent t-test, one way ANOVA } \\
\text { and regression and analysis, performed by SPSS-19 software. } \\
\text { Results: The results indicated that a significant positive relationship existed } \\
\text { between the information style (R=-.627 P=0.0001) and normative style } \\
\text { (R=- 0.598 P=0.0001), and commitment scale (R=0.564 P=0.0001) and } \\
\text { the students' achievement motivation. But there was a significant negative } \\
\text { relationship between the avoidance style (R= - } 0.337 \text { P=0.0001) and } \\
\text { achievement motivation of the high school students. } \\
\text { Conclusion: There was a significant positive relationship between the } \\
\text { styles of identity and achievement motivation of the students. Also, the } \\
\text { information style had the greatest relationship with the students' } \\
\text { achievement motivation. Thus, it seems that, in order to reach educational } \\
\text { progress, it is essential to pay attention to identity styles. }\end{array}$} \\
\hline $\begin{array}{l}\text { How to Cite this Article: } \\
\text { Ghasempour F, Azimi M, } \\
\text { Sanagoo A, Mobasseri AA. } \\
\text { Investigation of Relationship } \\
\text { between Identity Styles and } \\
\text { Achievement Motivation in } \\
\text { High School Students in the } \\
\text { City of Sari. Pajouhan Scientific } \\
\text { Journal. 2018; 16(2): 46-52. } \\
\text { DOI: 10.21859/psj.16.2.46 }\end{array}$ & \\
\hline & Keywords: Achievement Motivation; Identity Style; Students \\
\hline
\end{tabular}




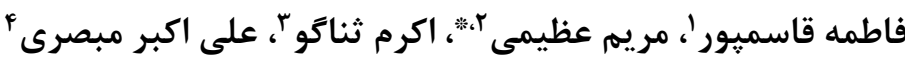

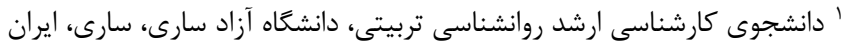

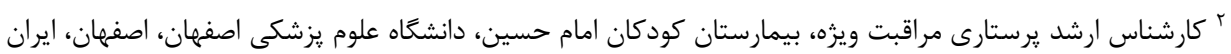

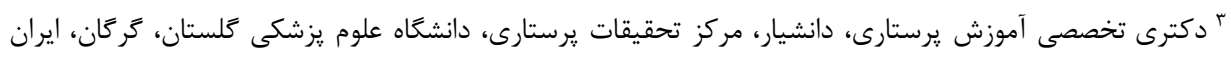

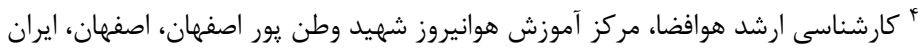 \\ * نويسنده مسئول: مريم عظيمى، بيمارستان كودكان امام حسين، دانشكاه علوم يزشكى اصفهان، اصفهان،ايران.
} ايميل: yahoo.com

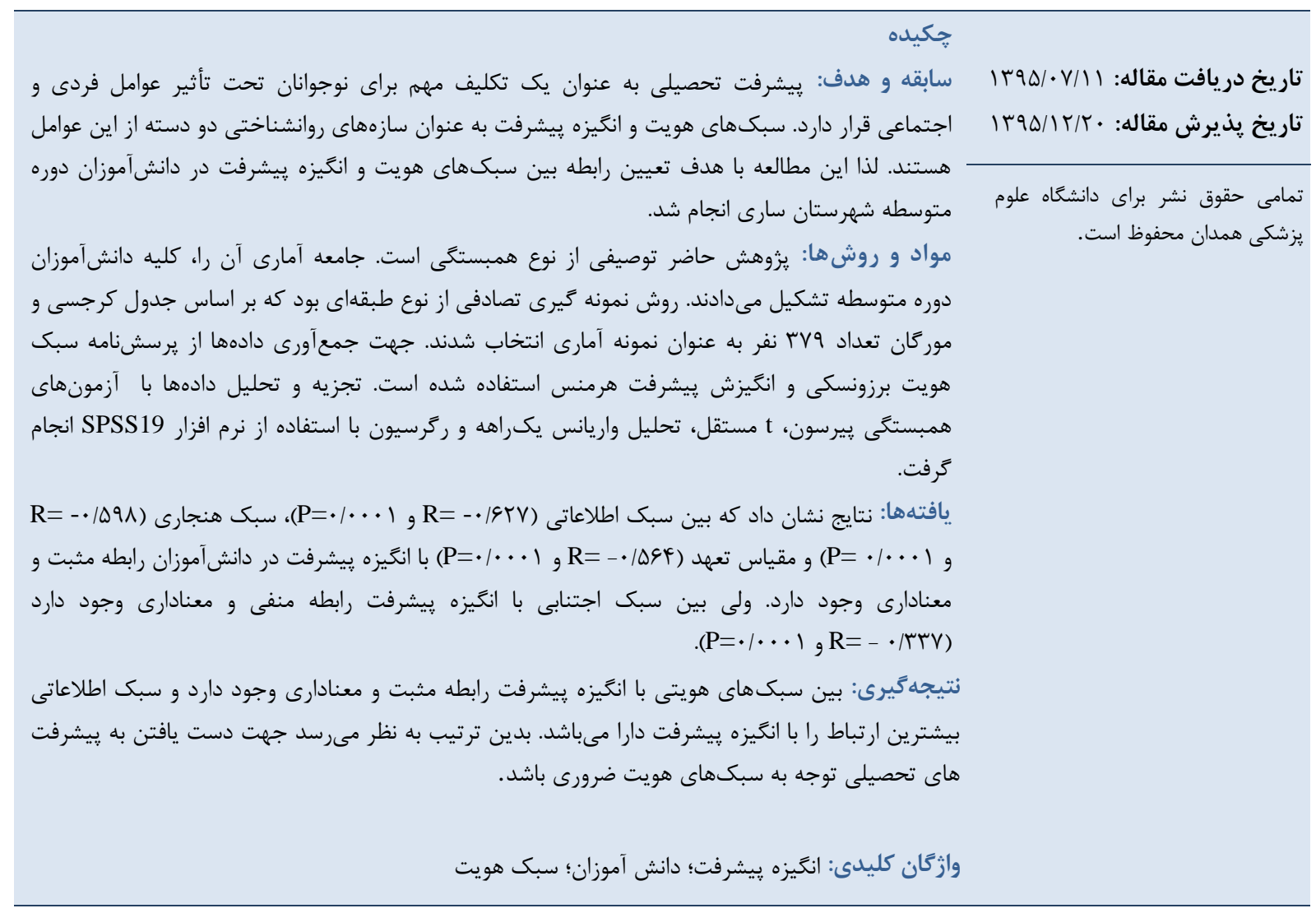

اساس تشكيل هويت، تلاشها و فعاليتهايى است كه علاقمند

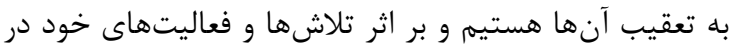

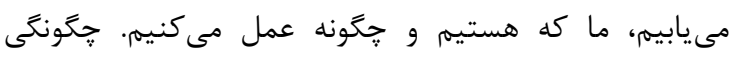
برداشتها و نظرات ديگران نسبت به ما، دمان در روشن كردن

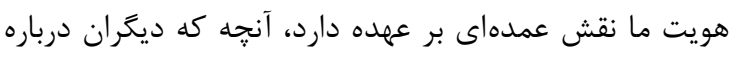

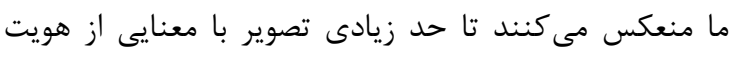
ماست [r] جهت رشد و ترقى، آشنايى با هويت به طور اعم و آشنايى
انسان و جايگاه او در جهان مدتهاست كه ذهن بشر را به مانه خود مشغول داشته و موضوع مناسبى براى تحقيق بوده است.

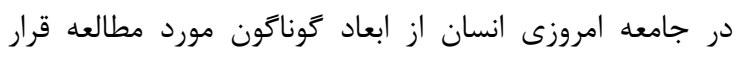

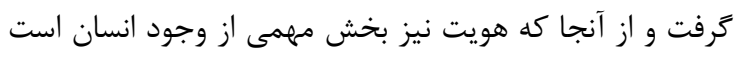

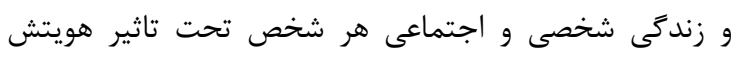

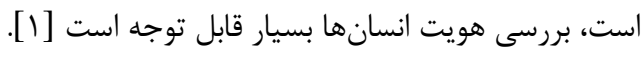

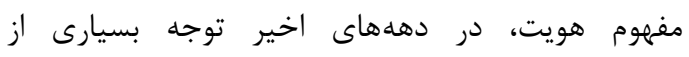
يروهشگران رشته هاى مختلف را به خود معطوف داشته داس است. 
عقايد را بدون ارزيابى آكاهانه مىيذيرند و درونى مىكنند و

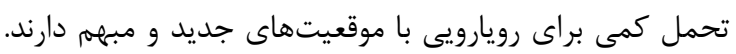

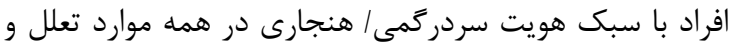

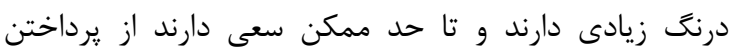

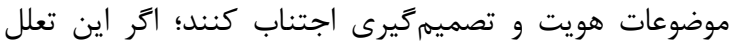

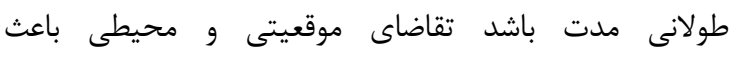

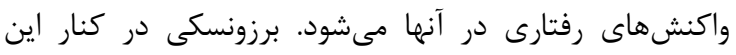

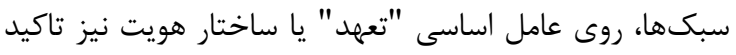

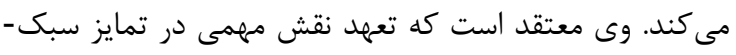

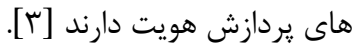

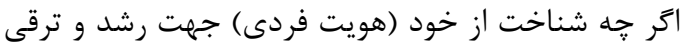

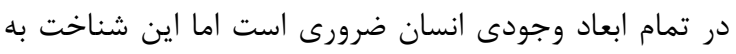

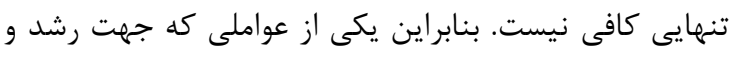

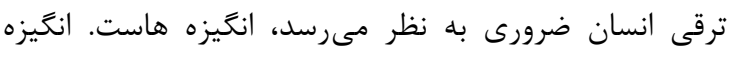

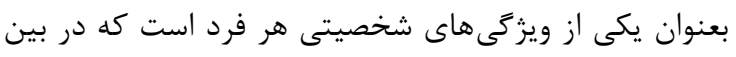

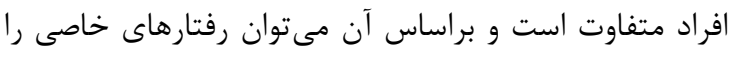

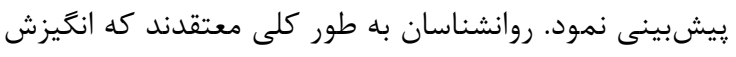

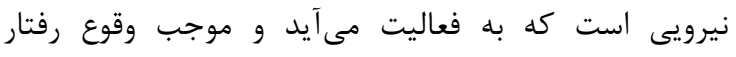

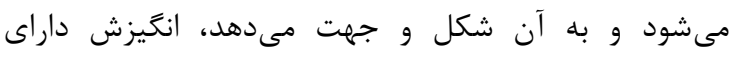

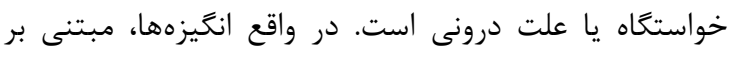

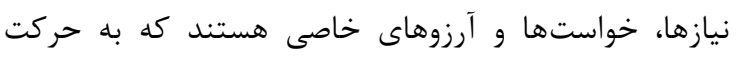

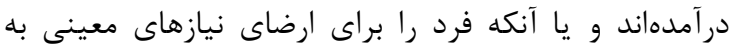

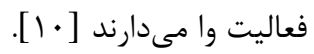

Acharya \& Joshi

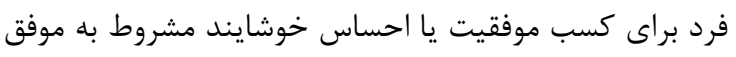

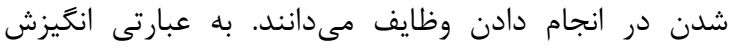

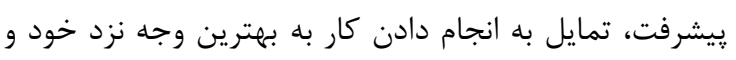
ديغران است كه با بيشرفت تحصيلى رابطه مثبت و معنى دارى

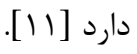

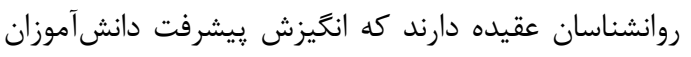

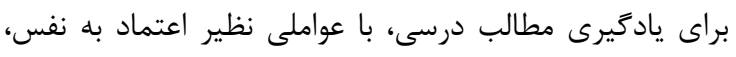

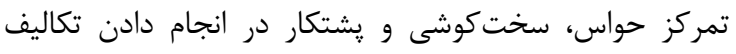

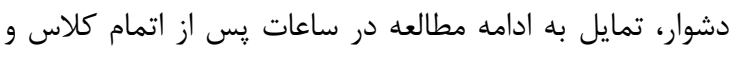

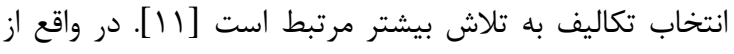

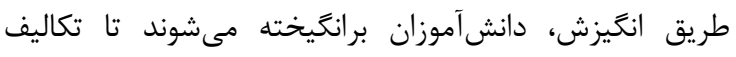

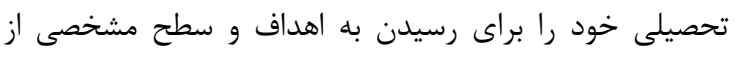

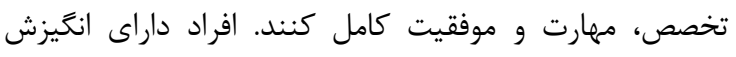

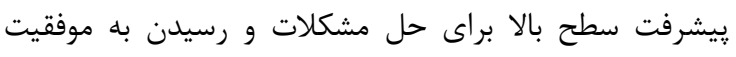

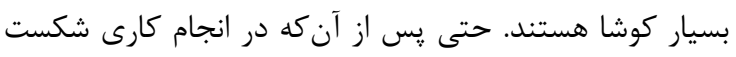

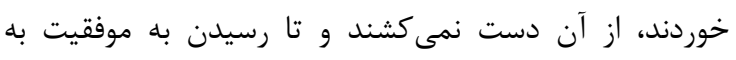

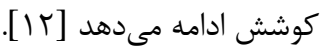

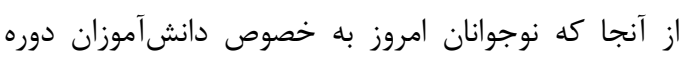

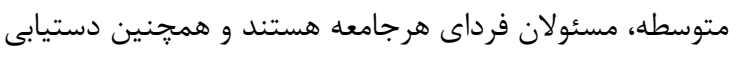
به هويت موفق و حل بحران هويت به شيوه موفقيت آميز و هماني
با هويت فردى و سبكهاى هويت به طور اخص ضرورتى انكار

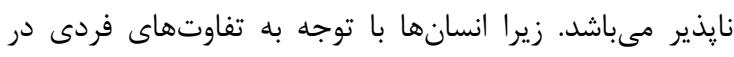

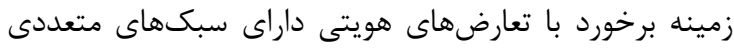

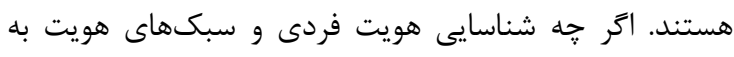

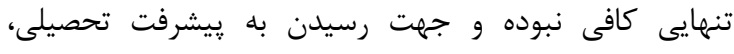

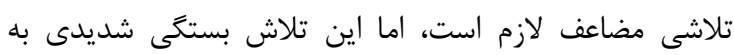

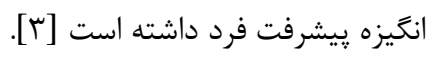

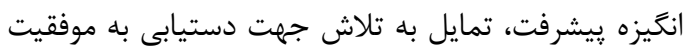

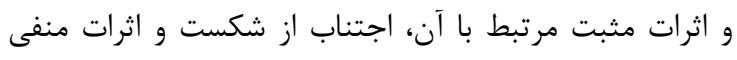

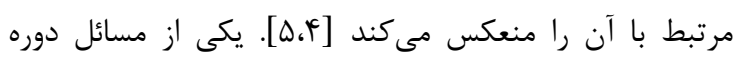

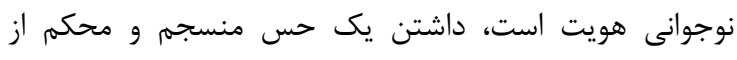

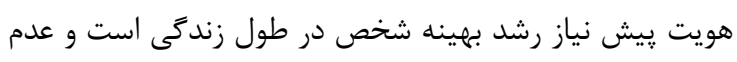

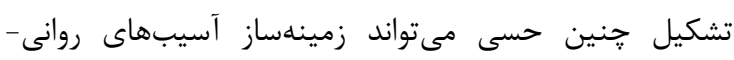

اجتماعى باشد [ع].

احساس خود، اساس شخصيت بزركسالى ما را را تشكيل

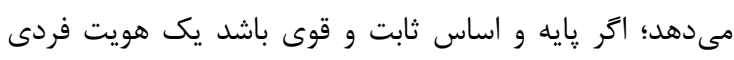

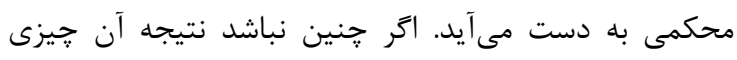

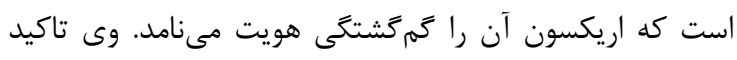

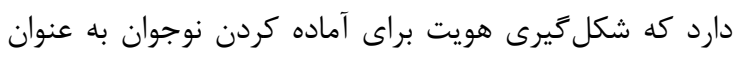

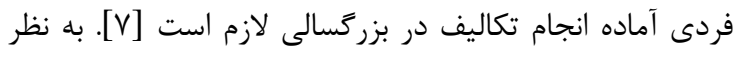

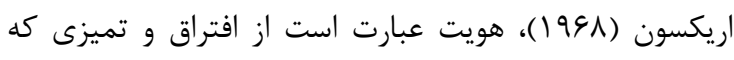

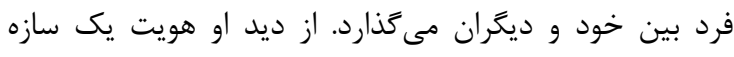

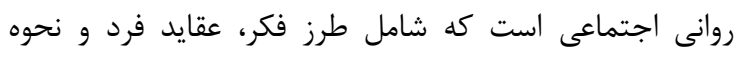

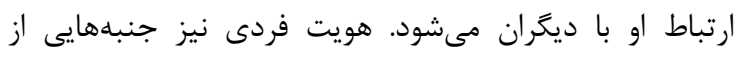

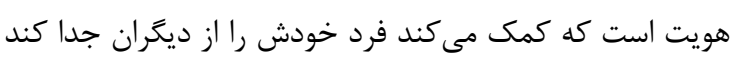

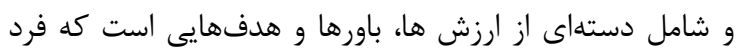

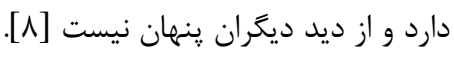

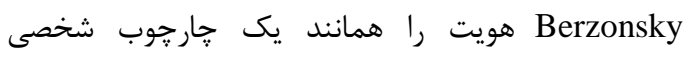

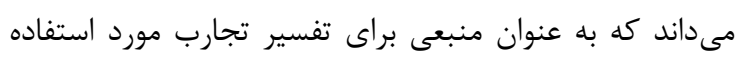

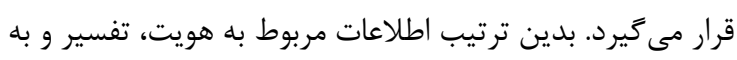

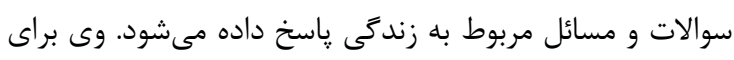

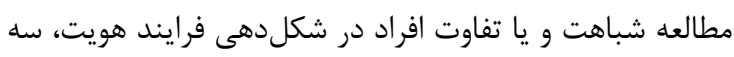

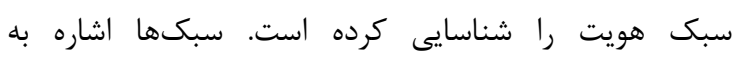

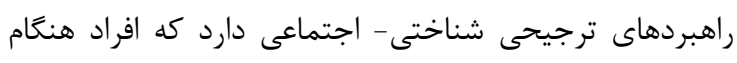

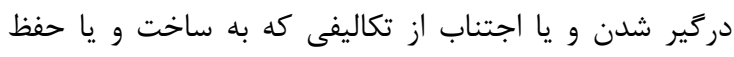

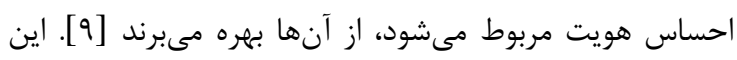

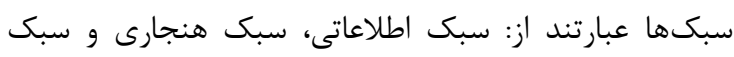

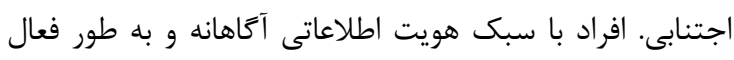

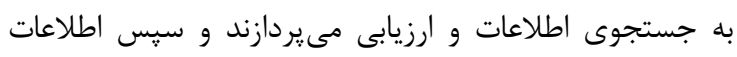

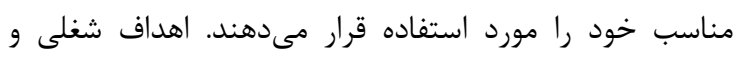

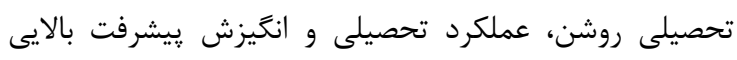

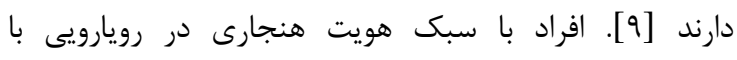

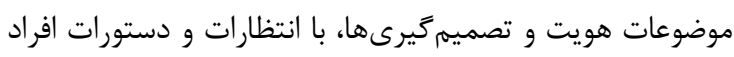

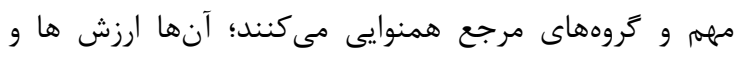


برخى سوالات به صورت مثبت و برخى ديگر به صورت منفى

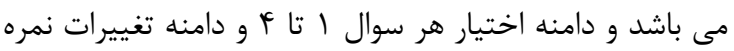

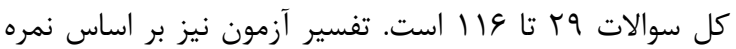
كل مى باشد. بدين معنى كه تمامى يرسش ها در جهت تعيين

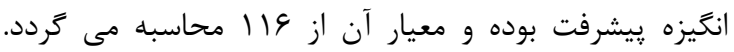

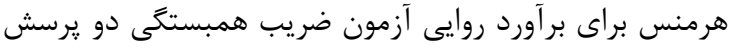

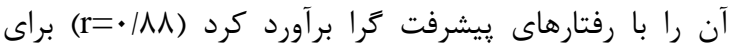

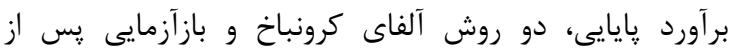

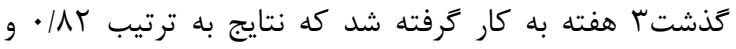

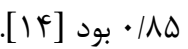

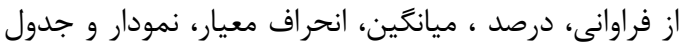

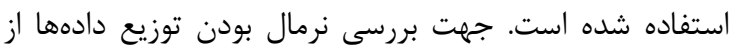

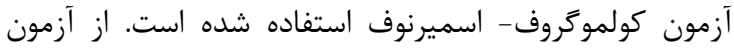

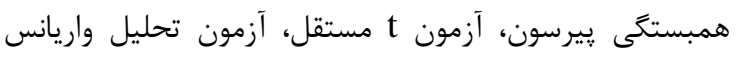

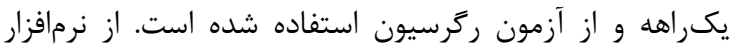
SPSS19 استفاده شد.

\section{افظتهن.}

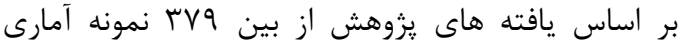

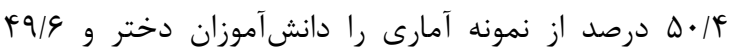

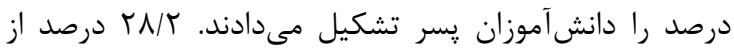

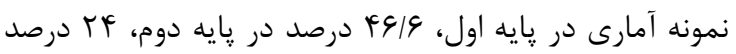

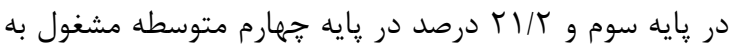

$$
\text { تحصيل بودند. }
$$

سبكهاى هويت داراى ميانگين عسب/ץ و انحراف معيار

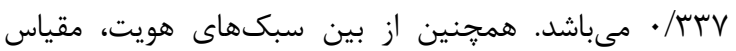

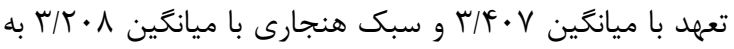

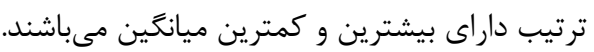

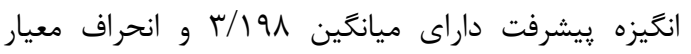
عسr/• مىباشد. كه اين امر نشان مىدهد ميانگين انخيزه

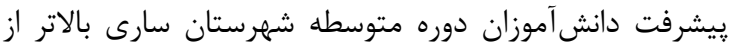
متوسط مىباشد. نتايج آزمون همبستكى ييرسون در مورد سبك اطلاعاتى و

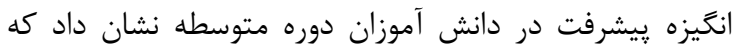
رابطه مثبت و معنادارى بين اين دو عامل وجود دارد.

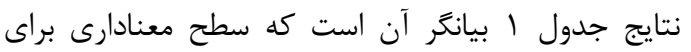

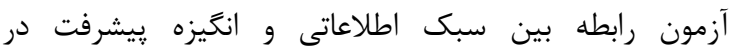

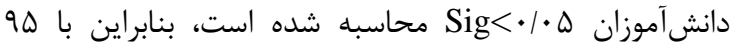

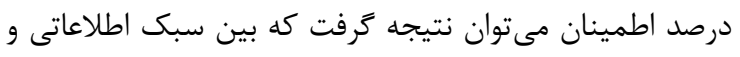

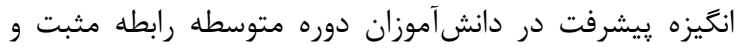

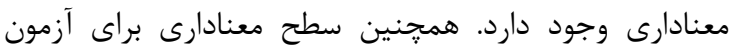

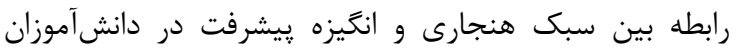

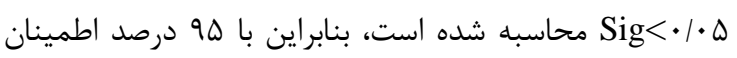

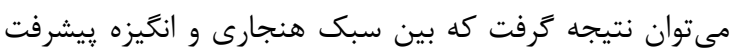

مثبت به استوار شدن شخصيت و رشد فرد كمك مى كند، لذا

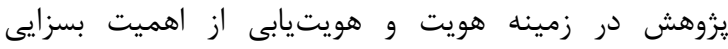

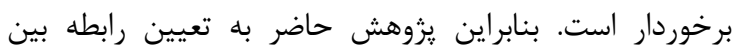

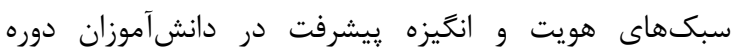
متوسطه شهرستان سارى يرداخت.

مواد و روشها

يزوهش حاضر توصيفى از نوع همبستگى است. جامعه

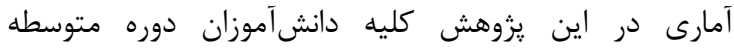

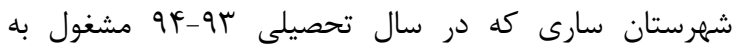

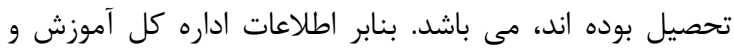
يرورش شهرستان سارى حجم جامعه آمارى • rVDG دانش آموز بودند. سيس حجم نمونه با استفاده از فرمول كوكران تعيين

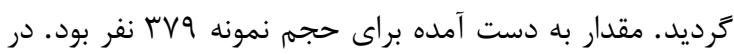

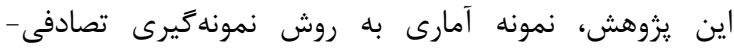
طبقهاى در جهار طبقه بر اساس پايه تحصيلى (يايههاى اول،

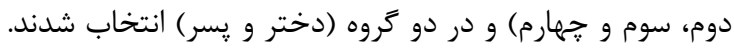

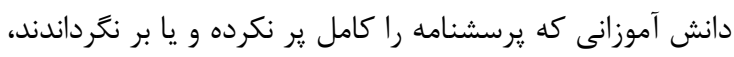

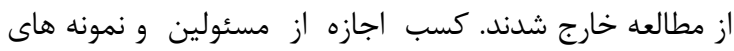
مطالعه و رضايت نامه شفاهى و حفظ بـى نامى از مسائل اخلاقى مانى

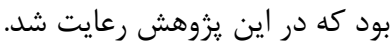

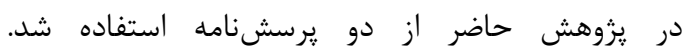

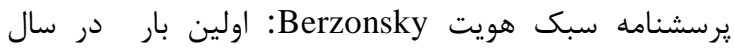

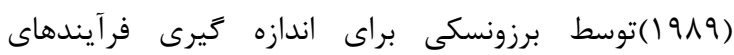

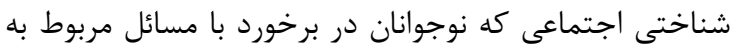

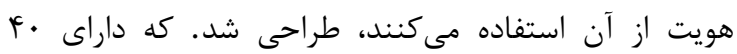

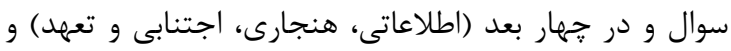

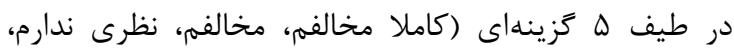

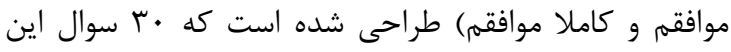

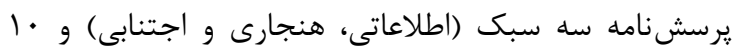

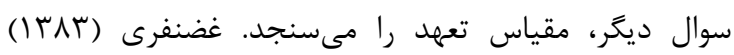

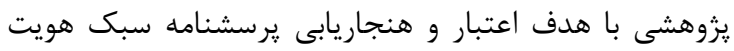

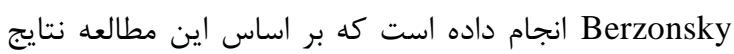

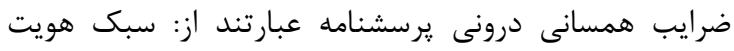

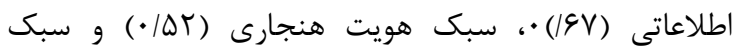

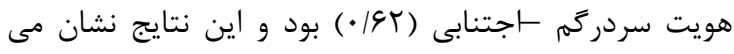

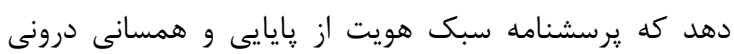

مناسبى برخوردار بود [11]]. يرسشنامه انخيزش ييشرفت هرمنس در سال (19V)

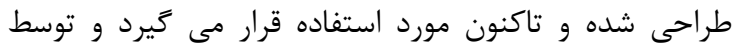

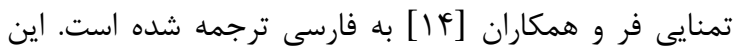

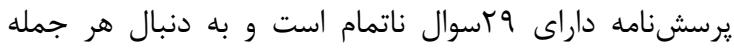

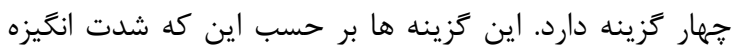

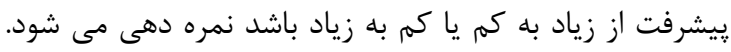




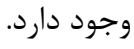

براى بررسى رابطه بين سبك هاى هويت و انگيزه يیشرفت برد

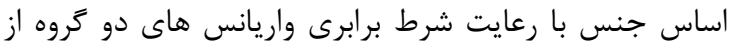

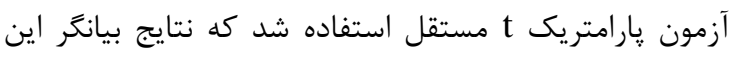
موضوع است كه بين دانش آموزان دختر و يسر در سبك هاى

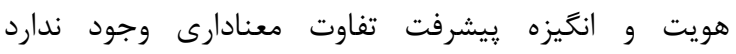

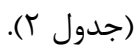

تفاوت ميانگينها در جهار گروه از لحاظ آمارى معنادار

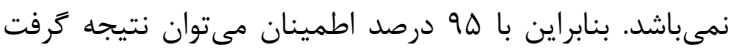

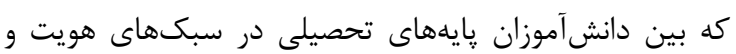

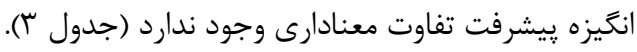

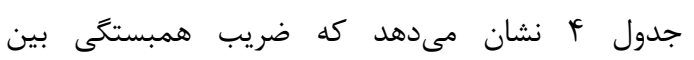

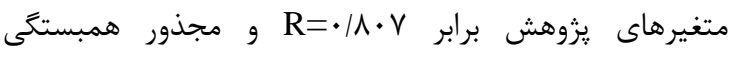

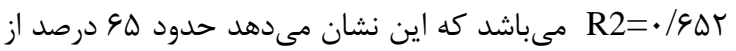

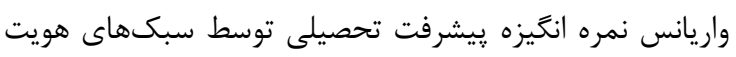

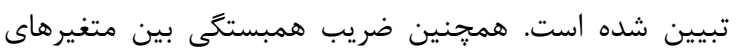

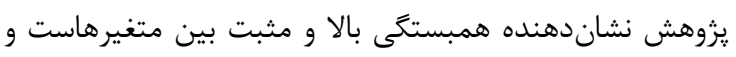

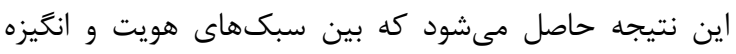

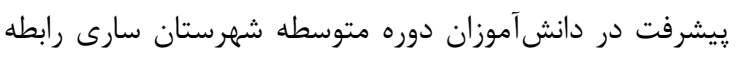
مثبت و معنادارى وجود دارد.
جدول ا: نتايج آزمون همبستخى ييرسون در مورد انگَيزه ييشرفت و سبك هاى مورد بررسى بير

\begin{tabular}{|c|c|c|}
\hline \multicolumn{2}{|c|}{ انتيزه بيشرفت } & متغير ها \\
\hline 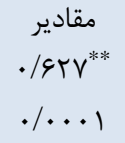 & مقدار همبستكى (r) شاخصها & سبك اطلاعاتى \\
\hline $\begin{array}{l}\cdot 109 \Lambda^{* *} \\
.1 . \cdots 1\end{array}$ & مقدار همبستكى (r) معنادارى (sig) & سبك هنجارى \\
\hline $\begin{array}{c}-\cdot / \mu r V^{* * *} \\
. / \cdots 1\end{array}$ & مقدار همبستكى (r) معنادارى (sig) & سبك اجتنابى \\
\hline $\begin{array}{l}\cdot / \Delta q \varphi^{* *} \\
. / \cdot \cdot 1 \\
r v q\end{array}$ & 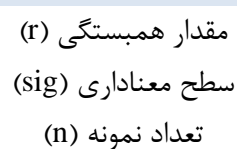 & تعهد \\
\hline
\end{tabular}

در دانش آموزان دوره متوسطه رابطه مثبت و معنادارى وجود

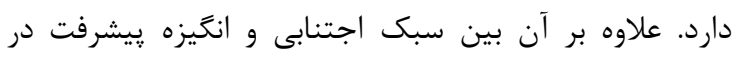

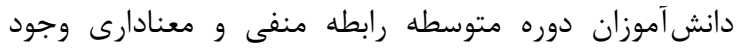

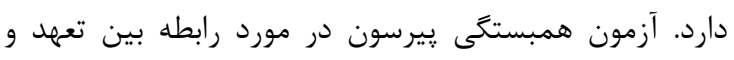

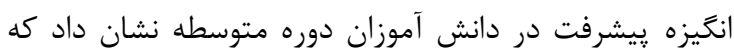

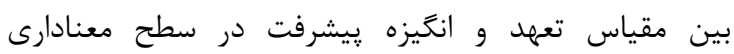

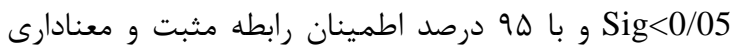

جدول r: نتايج آزمون t مستقل در مورد سبك هاى هويت و انخيزه بيشرفت

\begin{tabular}{|c|c|c|c|c|c|c|c|c|}
\hline معنادارى سطح & آز درجه & مقدار t & (همَّى واريانس معنادارى آماره) & انحراف معيار & ميانكَين & تعداد & جنس & متغير \\
\hline \multirow{2}{*}{$.1 .9 r$} & \multirow{2}{*}{ rVV } & \multirow{2}{*}{ I/99r } & \multirow{2}{*}{$\cdot / \cdot \wedge \Delta$} & $\cdot / r \cdot 9$ & r/rGF & 191 & دختر & \multirow{2}{*}{ سبكهاى هويت } \\
\hline & & & & . MFT & $r / r \cdot V$ & 111 & يسر & \\
\hline ./FTF & rVV & $\cdot / \Lambda$ &.$/ 9 \mathrm{VF}$ & . & T/T & 191 & دختر & انگيزه يِيشرفت \\
\hline
\end{tabular}

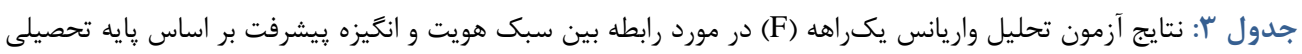

\begin{tabular}{|c|c|c|c|c|c|c|}
\hline سطح معنادارى & نسبت F & ميانگين مجذورات & درجه آزادى & مجموع مجذورات & منابع تغييرات & متغير \\
\hline \multirow{3}{*}{.1 .94} & \multirow{3}{*}{ F/FGT } & $\cdot / T \&$ & $r$ & $\cdot / V \wedge I$ & بين گروهها & \multirow{3}{*}{ سبكهاى هويت } \\
\hline & & \multirow[t]{2}{*}{$\cdot 11 \cdot 9$} & rVD & rq/GFT & درون تروهها & \\
\hline & & & rVA & F./FTr & كل & \\
\hline \multirow{3}{*}{. /vqF } & \multirow{3}{*}{. MFF } & \multirow{3}{*}{$\begin{array}{l}\cdot 1 \cdot 48 \\
. / 1 r \Delta\end{array}$} & r &.$/ 119$ & بين گروهها & \multirow{3}{*}{ انگيزه يِشرفت } \\
\hline & & & $r V \Delta$ & $0 \cdot 1019$ & درون گروهها & \\
\hline & & & rVA & $\Delta \cdot / 9 \Delta \Delta$ & كل & \\
\hline
\end{tabular}

جدول ₹f: خلاصه ارتباط بين سبك هويت و انخيزه يِيشرفت در دانش آموزان دوره متوسطه

\begin{tabular}{|c|c|c|c|}
\hline خطاى معيار تخمين & ضريب تعيين تعديل شده & مجذور همبستكى & ضريب همبستخى \\
\hline$\cdot / T I V$ & $\cdot|\&\rangle \wedge$ & - lबar & $\cdot \mid \mathrm{A} \cdot \mathrm{V}$ \\
\hline
\end{tabular}

انخيزه يِيشرفت در دانش آموزان دوره متوسطه رايطه مثبت و

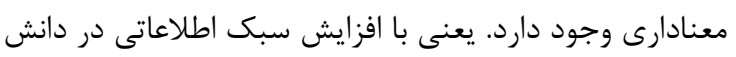

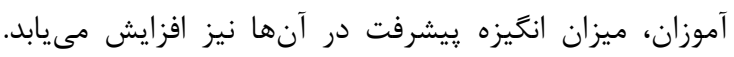

در اين يزوهش به بررسى رابطه بين سبك هاى هويت و

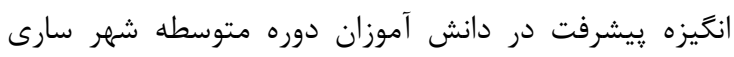

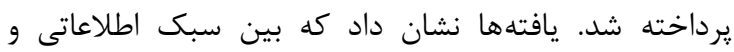


دوره متوسطه شهرستان سارى رابطه مثبت و معنادارى وجود

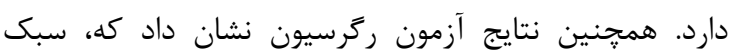

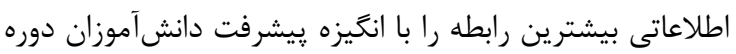

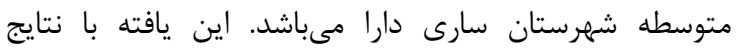

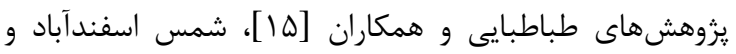

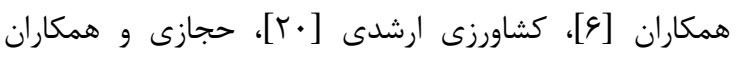

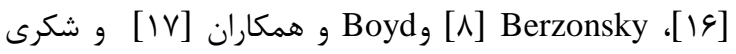

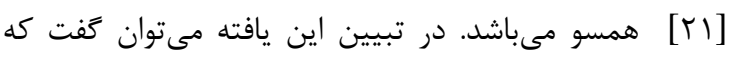

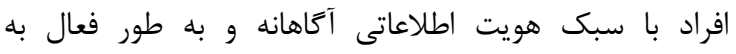

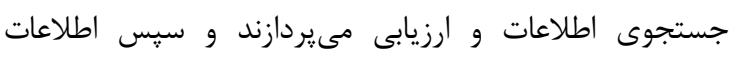

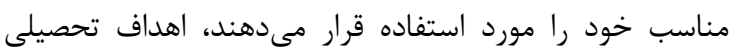

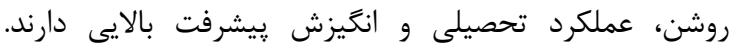
بنابراين داشتن بيشترين ارتباط سبك اطلاعاتى با انخيزه

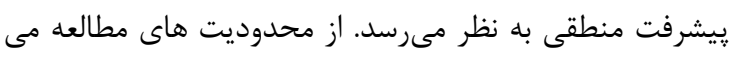

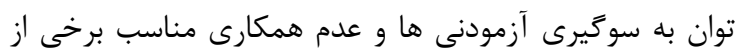

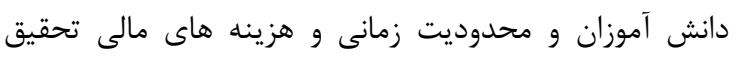

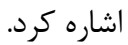

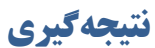

نتايج اين مطالعه نشان داد كه تمامى متغيرهاى يزوهشى، با انكيزهى بيشرفت، ارتباط معنادارى دارند، با اين

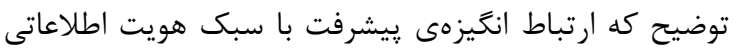

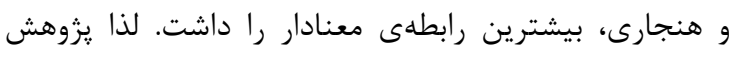

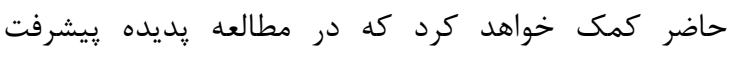
تحصيلى، نقش عوامل مهمى جون سبك هاى هويت و انگيزه

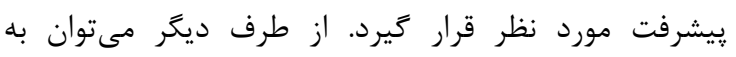

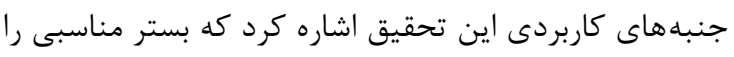

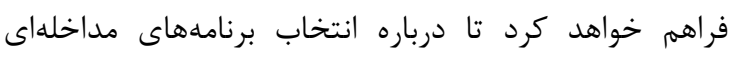
مناسب جهت رشد سبكهاى هويتى مؤثر، تصميمهاى لازم اتخاذ شود.

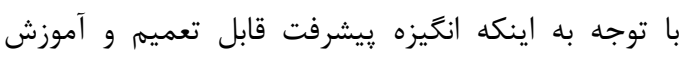

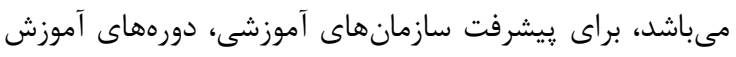

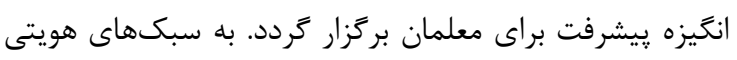

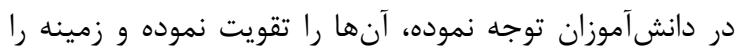
براى ييشرفت دانش آموزان فراهم نمايند.

\section{تشكر و قلروفاذى}

اين مطالعه حاصل پايان نامه دانشجوى كارشناسى ارشد ارشد

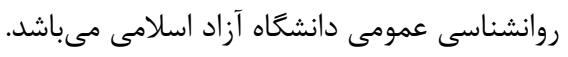

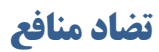
اين مطالعه براى نويسند
اين يافته با نتايج يزوهشهاى طباطبايى و همكاران [ها]، حجازى و همكاران [19]، Berzonsky وهمكاران [1] Boyd

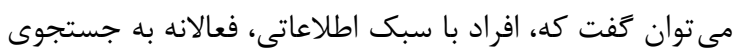

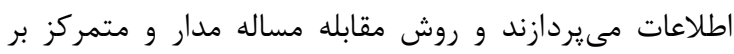

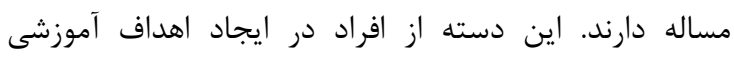

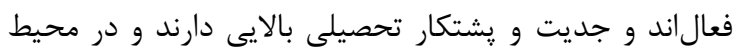

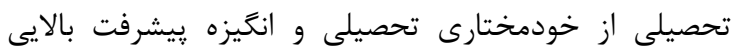

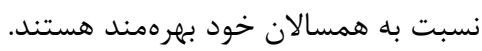

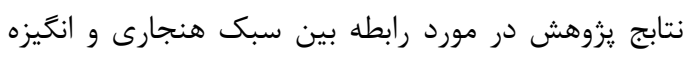

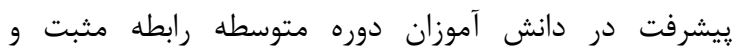

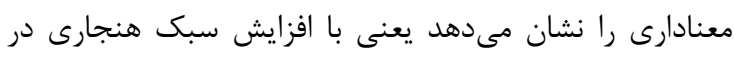

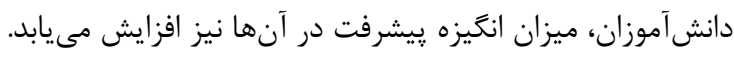

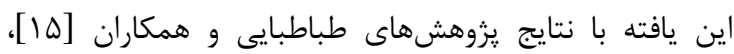

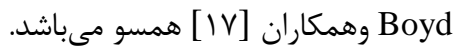

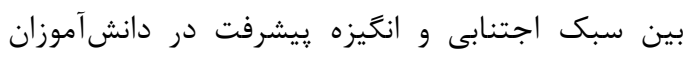

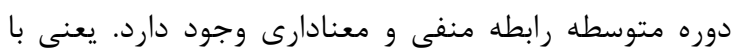

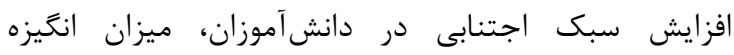

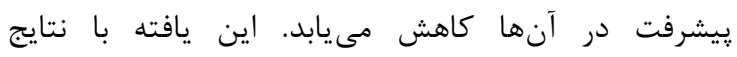

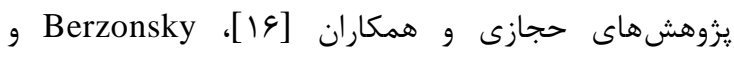

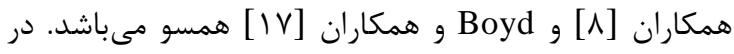

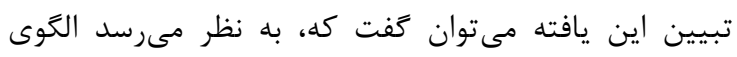

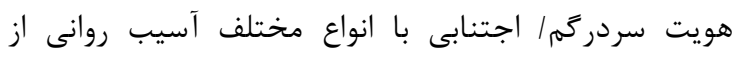

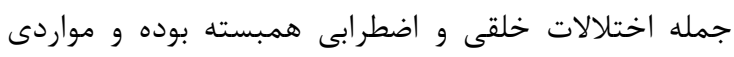

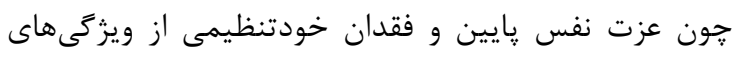

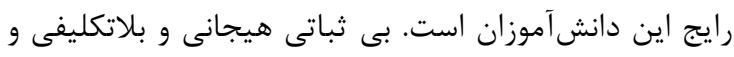

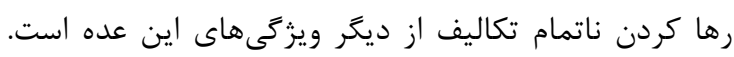

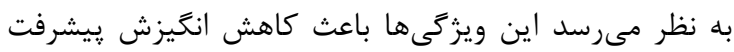
دانش آموزان مىشود. بين مقياس تعهد و انخيزه يِيشرفت در دانشآموزان دوره

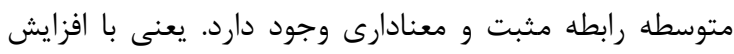

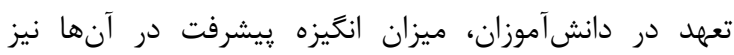

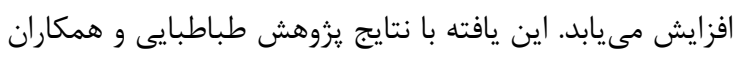

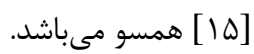

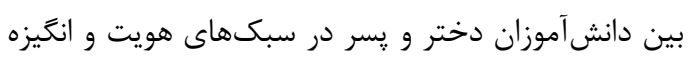
يشيشرفت تفاوت معنادارى وجود ندارد. اين يافته با نتايج

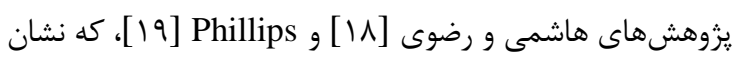

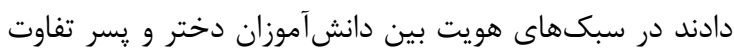

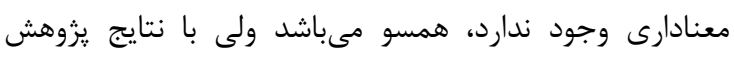

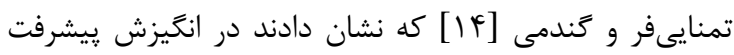

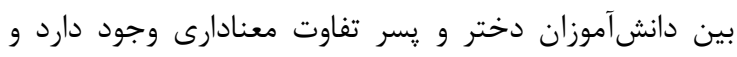

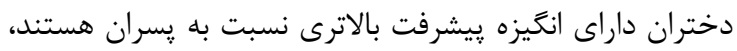
ناهمسو مىباشد. بين سبكهاى هويت و انكيزه ريشرفت در دانشآموزان 


\section{REFERENCES}

1. Imani M, Kyzaghan T. Factor's affecting women's social identity: Journal of Humanities University Al-zahra. 2004; 12 (44):79-107. (Persian)

2. Shafiabadi A, Nasseri Gh. Theories consultation and mental health. Tehran. University Publication Center. 2008. (Persian)

3. Barghi Moghadam J, Mosharaf Javadi B, Mozafari A, Garousi Farshi MT. Relationship Between Identity Styles With Motivation Factors And Success Feeling Journal Productivity Management (Beyond Management).2010; 3(11): 133 -155. (Persian)

4. Shahraray M, Valliollah F, Zaree A. The Relationship Between Attributional Styles And Achievement Motivation With Academic Achievement Among Students In Secondary School Majoring In Mathematic Sciences. Developmental Pscychology.2005;1(4): 1-9. (Persian)

5. Hossein Mardi AA, Hossein Mardi Z. Prediction of academic achievement based on emotional intelligence and achievement motivation among students of Islamic Azad University of Roudehen branch in 2013. Pajouhan Scientific Journal. 2015; 13 (3) :15-22. (Persian)

6. Shams Esfandabad H, Kakavand AR, Torabi Z. Relationship between attachment style and identity With public health and academic achievement of high school students in Qazvin. Journal New Thoughts On Education. 2012; 7(2) :108-129. (Persian)

7. Paixão MP, Panahandeh A. Predicting of Academic Performance by Identity Styles and Self-efficacy Beliefs (Personal and Collective) in Iranian High School Students. World Scientific News. 2017;61(2):186-91.

8. Jowkar B. The relationship between style of thinking and styles of identity. Journal of modern psychology (Psychology, University of Tabriz).2007;1(1):31-48. (Persian)

9. Berzinsky M D. Identity formation: The role of identity processing style and sognitive processes. Journal of Personality and Individual Differences. 2008; 44(3): 654655.

10. Abdi Zarrin S, Sajadian P, Shahyad SH, meamar A, azimi H. The relationship between identity styles and psychological well-being middles school girls in Qom. Tow monthly rise hygiene. 2009; 9(1):69-80. (Persian)
11. Acharya N, Joshi S. Influence of parents' education on achievement motivation of adolescents. Indian Journal Social Science Researches. 2009;6(1):72-9.

12. Radel R, Sarrazin P, Legrain P, Wild T C. Social contagion of motivation between teacher and student: Analyzing underlying processes. Journal of Educational Psychology. 2010; 102(3): 577-587.

13. Ghazanfar A. Validation and Standardization of Identity Style Inventory (ISI-6G). Studies of Education and Psychology. 2005;5(1):81-94.

14. Tamannaifar M R, Gandomi Z. Correlation between achievement motivation and academic achievement in university students. Educ Strategy Med Sci. 2011; 4 (1) :1519. (Persian)

15. Tabatabie N, Tabatabie S, Kakai Y, mohammadiAria A. The Relationship between Identity Styles and Responsibility with Educational Achievement in High School Students in Tehran. Social Welfare. 2012; 12 (44) :23-42. (Persian)

16. Hejazi E, Shahraray M, Farsinejad M, Asgary A. Identity styles and academic achievement: Mediating role of academic self-efficacy. Social Psychology of Education. 2009;12(1): 123-135. (Persian)

17. Kandell JJ, Lucas MS, Hunt PF, Boyd VS. Relationship between identity processing style and academic success in undergraduate students. Journal of College Student Development. 2003;44(2):155-67.

18. Hashemi N, Razavi A. The study and comparison of identify styles and related factors in adolescent students. Journal of Educational Psychology (Psychology and Education).2008 ;4(13):45-69.(Persian)

19. Phillips TM. Age-related differences in identity style: A cross-sectional analysis. Current Psychology. 2008;27(3): 205-15

20. Keshavarzi Arshadi F. Study in to the impact of identity style and emotional intelligence on academic performance and motive achievement. Andish Va Raftar.2009;4(13):4356. (Persian)

21. Shokri O, Shahraray M, Daneshvarpour V, Dastjerdi R. Individual differences in identity styles and academic performance: the role of identity commitment and psychological well-being. Research in Psychological Health.2007; 1(1):16-29. (Persian) 